\title{
Heather Skirton and Christine Patch: Genetics for the health sciences: a handbook for clinical healthcare
}

\author{
Second edition, ISBN 978-1-904842-70-5
}

\author{
Helen Thistlewood
}

Published online: 19 October 2010

(C) Springer-Verlag 2010

When first asked to write this book review, I thought to myself how it would be important to give a rounded report on both the book's strengths and weaknesses. After reading the book, however, I realised that it was difficult to find weaknesses.

The authors, Heather Skirton and Christine Patch, between them have over 30 years of experience in clinical genetics. Their experience of explaining genetics in their professional roles shines through in the way they have written the book. They make complex genetic principles interesting and understandable. The book does not baffle or patronise.

The book is easily navigated. It is broken down into clear chapters that are ordered in a pleasingly logical way. The first chapter "sets the scene" by introducing the reader to important concepts related to genetic health care including issues, such as ethical practice, the different forms of genetic testing, and the impact of genetic conditions on families. The next chapters discuss the family tree, counselling issues, genetic science, and public health genetics. The remaining chapters explore the core topics relating to particular life stages from preconception to older adulthood. It engages the reader from the start when it introduces seven 'core' families that reappear throughout the book to highlight a number of key issues.

The text is peppered with clear illustrations, useful step by step guides, practical checklists, and test yourself sections making the book lively and dynamic. The test yourself sections make the book student friendly and would also make good teaching aids to lecturers and tutors. At the start of the book there is a list of helpful websites and at the end of each chapter there is a list of resources for those who wish to extend their knowledge.

One of the main strengths of this book is its refreshingly practical approach. All too often books can be written in a way in which it is difficult for the reader to transfer the knowledge that they have gained into their day-to-day practice. The introduction states that "the aim of this book is to enable those in healthcare to update their knowledge on topics related to genetics and genomics that have an impact in their daily work and apply it usefully in patient care". Given the fact that genetics has increasingly become a core component in a number of specialties, one would think that meeting this aim for all would be a tall order. This book, however, eloquently does so using case examples and key practice points boxes throughout to demonstrate the clinical application of the topic under discussion. Another main strength of the book is the way in which it promotes individualised care by enabling the reader to consider the impact of genetic conditions from the patients' point of view.

'Genetics for the Health Sciences' brings genetics into common healthcare settings. It is highly recommended as an essential text for health care professionals in roles across all specialties. It is also recommended to students, lecturers, social scientists, and to anyone who has an interest in genetics and wishes to extend their knowledge. It is a joy to read and could be read from cover to cover. 